Arq. Bras. Med. Vet. Zootec., v.65, n.4, p.946-954, 2013

\title{
Isolamento e caracterização de células mesenquimais do tecido adiposo de cães
}

\author{
[Isolation and characterization of canine adipose-derived mesenchymal stem cells] \\ L.F.L. Patricio ${ }^{1}$, C.L.K. Rebelatto ${ }^{2}$, P.R.S. Brofman ${ }^{2}$, B.B. Maciel $^{1}$, O.C. Beltrame ${ }^{1,3}$, \\ H.F.V. Brito ${ }^{1}$, R. Locatelli-Dittrich ${ }^{1,3^{*}}$ \\ ${ }^{1}$ Programa de pós-graduação - Universidade Federal do Paraná (UFPR) - Curitiba, PR \\ ${ }^{2}$ Pontifícia Universidade Católica do Paraná (PUC-PR) - Curitiba, PR \\ ${ }^{3}$ Universidade Federal do Paraná (UFPR) - Curitiba, PR
}

\begin{abstract}
RESUMO
As células-tronco mesenquimais (CTMs) diferenciam-se em várias linhagens e têm potencial de utilização na medicina regenerativa. As CTMs podem ser isoladas de vários tecidos de animais adultos. O objetivo deste estudo foi o isolamento das CTMs do tecido adiposo de cães, seu cultivo e diferenciação. Foram coletadas amostras de tecido adiposo subcutâneo de cinco cães. As CTMs foram isoladas, obtendo-se $146.803( \pm 49.533)$ células/g, cultivadas e diferenciadas em osteoblastos, adipócitos e condrócitos. Avaliaram-se a cinética do crescimento, a morfologia e a viabilidade celular. A caracterização citoquímica comprovou a natureza mesenquimal das células isoladas. $\mathrm{O}$ cultivo foi iniciado com 20.000 células $/ \mathrm{mL}$, verificando-se crescimento rápido até 72 horas (220.000 células/mL), fase exponencial entre 72 e 192 horas (455.000 células/mL), seguida de platô por saturação da densidade com 240 horas (355.000 células $/ \mathrm{mL}$ ). A viabilidade celular variou entre 96 e 100\%. As CTMs em cultivo são fibroblásticas, fusiformes, com citoplasma basofílico e núcleo esférico. O comprimento médio das células variou entre 80,85 e $98,36 \mu \mathrm{m}$, a largura média entre 17,40 e $28,79 \mu \mathrm{m}$ e o diâmetro médio do núcleo entre 15,46 e $17,74 \mu \mathrm{m}$.
\end{abstract}

Palavras-chave: morfologia celular, diferenciação celular, células-tronco, panículo adiposo

\begin{abstract}
The applications of mesenchymal stem cells (MSCs) are becoming increasingly more promising for regenerative medicine and tissue engineering fields. MSCs can be isolated from adult animals from a variety of tissues, such as the adipose. This study focused on the isolation, culture and differentiation of MSCs from canine adipose tissue. Samples of subcutaneous adipose tissue from five dogs were collected. These cells were isolated, cultured and differentiated into osteoblasts, adipocytes and chondrocytes. We obtained 146,803 $( \pm 49,533)$ cells $/ g$. Growth kinetics and viability studies were conducted during cell culture and the evaluation of cell differentiation was successfully performed by cytochemistry. The cell cultures were initiated with 20,000 MSCs/ml. Rapid growth was observed at 72 hours $(220,000$ cells $/ \mathrm{ml})$, the exponential phase between 72 and 192 hours $(455,000$ cells $/ \mathrm{ml})$ and saturation at 240 hours $(355,000$ cells $/ \mathrm{ml})$. The cellular viability ranged from 96 to $100 \%$. MSCs in culture are fibroblastic cells, fusiform with basophilic cytoplasm and spherical nucleus. The length and width means of the cells and nuclear diameter ranged from 80.85-98.36 $\mu \mathrm{m}, 17.40-28.79 \mu \mathrm{m}$ and 15.46-17.74 $\mu$ m respectively.
\end{abstract}

Keywords: ADMSC, cell differentiation, stem cell, adipose tissue

\section{INTRODUÇÃO}

Células-tronco mesenquimais (CTMs) são progenitoras multipotentes capazes de se diferenciarem em vários tecidos (Pittenger, 1999), preservando a própria população (Zago, 2005). As CTMs não diferenciadas exibem

Recebido em 29 de março de 2012

Aceito em 9 de abril de 2013

*Autor para correspondência (corresponding author)

E-mail: roslocdi@ufpr.br morfologia fibroblástica e padrão característico de marcadores de superfície. Contudo, não existe ainda uma distinção definida entre marcadores de CTMs de medula óssea, tecido adiposo, fibroblastos, periósteo e de músculos, e marcadores comerciais não estão disponíveis para as diferentes espécies animais (Martin et al., 2002). 
A fonte mais comum para isolamento de CTMs é a medula óssea, porém outros tecidos, como periósteo, músculos e tecido adiposo, são fontes dessas células (IM et al., 2005). Os primeiros isolamentos de células do tecido adiposo ocorreram na década de 60 com gordura de epidídimo de ratos (Rodbell, 1966). Em seres humanos, isolamentos de CTMs do tecido adiposo são geralmente realizados com amostras obtidas por lipoaspiração.

Segundo Neupane et al. (2008), tem-se mais sucesso no isolamento de CTMs com tecido adiposo subcutâneo, comparado com tecido do omento e de depósitos inguinais. Os autores realizaram isolamento de CTMs de cães, por digestão com colagenase tipo I-A, e as diferenciaram em tecido ósseo, cartilaginoso e adiposo, com confirmação por citoquímica, reação em cadeia da polimerase em tempo real (RT-PCR) e imunocitoquímica. Contudo, a caracterização morfológica não foi realizada.

Não existem, até o presente, relatos de avaliação da cinética e características morfológicas de CTMs de cães. Os objetivos deste trabalho foram o isolamento, o cultivo, a diferenciação e a caracterização morfológica de CTMs do tecido adiposo de cães.

\section{MATERIAL E MÉTODOS}

Este trabalho foi aprovado pela Comissão de Ética no Uso de Animais do Setor de Ciências Agrárias da Universidade Federal do Paraná (Ceua-SCA/UFPR), sob protocolo $n^{\circ}$. 017/2008.

Foram coletadas amostras (15 a $22 \mathrm{~g})$ de tecido adiposo subcutâneo abdominal de cinco cadelas hígidas, com idades entre 10 meses e 10 anos, durante procedimento de ovário-histerectomia eletiva. O protocolo para o isolamento das CTMs foi adaptado de Wagner et al. (2005).

Cada amostra foi colocada em uma placa de Petri, lavada duas vezes com solução de tampão fosfato (PBS) estéril, macerada com bisturi e transferida para frasco com solução de colagenase tipo I (Invitrogen, EUA) para digestão enzimática, a $37^{\circ} \mathrm{C}$, por 30 minutos, em agitação constante. $\mathrm{O}$ sobrenadante foi desprezado, e a amostra centrifugada a 2.500 RPM por 10 minutos em tubo Falcon (Tecno Plastic Products, Suiça). Retirou-se novamente o sobrenadante, sendo adicionados $10 \mathrm{~mL}$ de PBS para centrifugação a 1.000 RPM por 10 minutos. O sobrenadante foi desprezado, e as células ressuspendidas em meio de cultivo de Eagle modificado por Dulbeco e em meio de Ham F12 (DMEM/F12 - Invitrogen, EUA). As células isoladas foram plaqueadas na concentração de $1 \times 10^{6}$ células $/ \mathrm{mL}$ de meio, incubadas a $37^{\circ} \mathrm{C}$ com $5 \%$ de $\mathrm{CO}_{2}$ para crescimento e expansão. $\mathrm{O}$ cultivo foi realizado em frascos de poliestireno (Tecno Plastic Products, Suiça) de $25 \mathrm{~cm}^{2}$, com meio DMEM/F12 com $15 \%$ de soro fetal bovino (SFB - Cultilab, Brasil) e $1 \%$ de antibiótico (penicilina 100UI/mL e estreptomicina $100 \mu \mathrm{g} / \mathrm{mL}$ - Invitrogen, EUA). A primeira troca de meio foi realizada entre 48 e 72 horas de cultivo, e as demais entre 72 e 96 horas, eliminando-se as células não aderidas. Os frascos foram observados em microscópio invertido para avaliação da morfologia e do crescimento celular. Quando atingiram 80 a $85 \%$ de confluência, foi feita a passagem, utilizando-se tripsina $0,5 \%$ (Amresco, EUA) para individualização das células, na proporção de $1,0 \mathrm{~mL} /$ frasco, durante quatro minutos, a $37^{\circ} \mathrm{C}$. A seguir, a enzima foi inativada em $1,0 \mathrm{~mL}$ de $\mathrm{SFB}$, as células foram transferidas para tubo Falcon com 4,0mL de meio DMEM/F12, centrifugadas a $1.500 \mathrm{RPM}$ por 10 minutos e ressuspendidas em $1,0 \mathrm{~mL}$ do mesmo meio. Avaliaram-se o rendimento e a viabilidade em câmara de Neubauer, utilizando-se $10 \mu \mathrm{L}$ do corante vital azul de tripan 0,4\% (Sigma-Aldrich, EUA), em $50 \mu \mathrm{L}$ da suspensão de células, para leitura após cinco minutos. Realizou-se novo plaqueamento em frascos de cultivo, na concentração média de $0,93 \times 10^{6}$ células $/ \mathrm{mL}$.

Para avaliar a cinética do crescimento celular, foi estabelecida a curva de crescimento, com células de terceira passagem. Após a tripsinização, uma suspensão com 20.000 células/mL foi distribuída em 20 frascos de cultivo com $25 \mathrm{~cm}^{2}$ de área de crescimento, os quais foram incubados a $37^{\circ} \mathrm{C}$ com $5 \%$ de $\mathrm{CO}_{2}$. A cada $24 \mathrm{~h}$ as células de dois frascos foram tripsinizadas para avaliação de rendimento e viabilidade. Os demais frascos eram mantidos em incubação por até 10 dias, com trocas de meio a cada três ou quatro dias.

Para diferenciação, utilizaram-se células de terceira a sexta passagem, conforme estas atingiam número para início da indução 
(Dvorakova, 2008). A confluência desejada (80$85 \%$ ) foi obtida em $24 \mathrm{~h}$.

As células foram induzidas à diferenciação em osteoblastos, adipócitos e condrócitos em período de 21 dias. Para osteoblastos e adipócitos, esta foi realizada em duplicata, em placas de poliestireno de 24 poços, com 30.000 células/poço. No poço foi colocada uma lamínula de vidro de $13 \mathrm{~mm}$ de diâmetro (Glasstecnica, Brasil) esterilizada.

Para cada amostra foram utilizados quatro poços, sendo dois para controle, nos quais foi utilizado o meio DMEM/F12 com 15\% de SFB, e dois para diferenciação com o mesmo meio, acrescido de dexametasona $(0,1 \mu \mathrm{mol} / \mathrm{L}), \beta$-glicerolfosfato $(10 \mathrm{mmol} / \mathrm{L})$ e ascorbato $(50 \mu \mathrm{mol} / \mathrm{L})$. Os meios foram trocados três vezes por semana. Os meios retirados foram armazenados para determinação da fosfatase alcalina (FA), dosada em aparelho semiautomático SBA-200 (Celm, Brasil), utilizando-se o kit "Alkaline Phosphatase Liquicolor" (Human do Brasil, Brasil) e soro controle "Serodos plus" (Human do Brasil, Brasil).

Para indução em adipócitos foram testados dois meios. No tratamento I, meio DMEM/F12 com $15 \%$ de SFB, adicionado de dexametasona $(1 \mu \mathrm{mol} / \mathrm{L})$, insulina $(5 \mu \mathrm{g} / \mathrm{mL})$ e indometacina $(60 \mu \mathrm{mol} / \mathrm{L})$, trocado três vezes por semana. No tratamento II foi utilizado meio comercial para indução adipogênica (hMSC Adipogenic Induction - Cambrex, EUA), durante três dias, em alternância com o meio de manutenção (hMSC Adipogenic Maintenance - Cambrex, EUA), por dois dias, conforme orientações do fabricante. Como controle foi utilizado meio comercial (MSCGM SingleQuots - Cambrex, EUA), trocado três vezes por semana.

A diferenciação condrocítica foi feita em tubos Falcon de $15 \mathrm{~mL}$, em sistema de cultivo de micromassa, com 200.000 células, conforme descrito por Sekiya et al. (2001). Os tubos foram centrifugados por 10 minutos a 1.500 RPM. O meio sobrenadante foi substituído por meio indutor ou pelo controle e novamente centrifugado. Foram utilizados dois meios de diferenciação. No tratamento I, empregou-se meio DMEM/F12 com $15 \%$ de SFB adicionado dos indutores TGFß1 (fator de transformação de crescimento $\beta 1-10 \mathrm{ng} / \mathrm{mL})$, insulina $(0,5 \mu \mathrm{g} / \mathrm{mL})$ e ácido ascórbico $(50 \mu \mathrm{mol} / \mathrm{L})$. No tratamento II, utilizou-se meio comercial para indução condrogênica (hMSC Chondrogenic SingleQuots - Cambrex, EUA) e, para controle, meio comercial MSCGM SingleQuots. Os meios foram trocados três vezes por semana.

Os osteoblastos e adipócitos foram corados em lamínulas dentro das placas. Após 21 dias de indução, o meio foi retirado e cada poço lavado duas vezes com PBS em temperatura ambiente. O material foi fixado em líquido de Bouin por sete minutos. As células foram lavadas duas vezes com álcool $70 \%$ e duas vezes com água purificada (Mili-Q - Millipore, EUA). A seguir, adicionou-se o corante específico para cada linhagem. Para osteoblastos, utilizou-se o corante Alizarina Red $S$ (Fluka Chemie) e, como contraste, Light Green (Sigma-Aldrich, EUA); para adipócitos, o corante Oil Red $O$ (SigmaAldrich, EUA) por uma hora e hematoxilina por 30 segundos.

Os agregados celulares de condrócitos foram fixados em formaldeído $10 \%$ por uma hora em temperatura ambiente, desidratados em diluições seriadas de etanol e embebidos em blocos de parafina. Os blocos foram cortados com espessura de $4 \mu \mathrm{m}$ e corados com azul de tripan $0,4 \%$, para detecção dos mucopolissacarídeos da matriz intracelular.

Para cada amostra de tecido adiposo foram realizadas três passagens $(\mathrm{P} 1, \mathrm{P} 2$ e $\mathrm{P} 3)$, sendo transferidas de cada uma 20.000 células, as quais foram divididas em quatro placas de Petri descartáveis, estéreis, com área de crescimento de $9,03 \mathrm{~cm}^{2}$, contendo uma lamínula de vidro redonda $(13 \mathrm{~mm}$ de diâmetro - Glasstecnica, Brasil).

As placas foram mantidas em incubadora a $37^{\circ} \mathrm{C}$ com $5 \%$ de $\mathrm{CO}^{2}$ em meio de cultivo DMEM/F12 suplementado com $15 \%$ de soro fetal bovino e $1 \%$ de antibiótico (penicilina 100UI/mL e estreptomicina $100 \mu \mathrm{g} / \mathrm{mL}$ ). Com 24, 48, 72 e 96 horas uma lamínula de cada passagem, de todas as amostras, foi retirada para coloração com corante de Wright (Laborclin, Brasil), fixação em lâmina de vidro e observação em microscópio óptico para descrição da morfologia celular e medição com auxílio do programa Motic Image Plus 2.0 (Xiamen, China). Foram medidas 50 células de cada lâmina, totalizando 3.000 células, 
sendo avaliados comprimento, largura e diâmetro do núcleo. Para avaliação estatística, foi realizado o teste ANOVA.

\section{RESULTADOS E DISCUSSÃO}

O número de células isoladas por amostra variou com o tamanho e a qualidade desta e com a quantidade de tecido fibroso e sangue. Em média, foram obtidas $146.803 \quad( \pm 49.533)$ células/g de tecido adiposo, inferior às 528.000 células/g obtidas por Neupane et al. (2008) de três cães, mas compatível às 209.241 células/g que Colleoni et al. (2009) obtiveram de 11 cavalos.

A curva de crescimento celular das CTMs está apresentada na Fig. 1. Observou-se rápido crescimento inicial, seguido por fase regular (exponencial), representada pela porção reta do gráfico, e fase de saturação da densidade, representada pela interrupção do crescimento celular (platô), similares aos resultados encontrados por Colleoni et al. (2009), que estudaram a cinética do crescimento de CTMs do tecido adiposo de cavalos. A viabilidade celular avaliada da primeira à sexta passagem de cultivo variou de $96-100 \%$.

Dominici et al. (2006) propuseram três critérios para caracterizar CTMs: aderência às superfícies plásticas, potencial de diferenciação em osteoblastos, condrócitos e adipócitos, e expressão de marcadores de superfície específicos. Entretanto, a caracterização de marcadores de superfícies para CTMs de animais é desafiadora porque não há disponibilidade comercial destes para as diferentes espécies, e nem todo marcador utilizado para homens e murinos apresenta reação cruzada com outras espécies (Tapp et al., 2009). Outros estudos em animais, como os realizados por Csaki et al. (2007) e Carvalho et al. (2009), foram limitados em relação ao número de marcadores utilizados e apresentaram resultados diferentes. Contudo, Pittenger et al. (1999) definiram as CTMs como fibroblastos com capacidade para se diferenciarem em três linhagens principais: osteoblástica, adipocítica e condrocítica, quando submetidos a estímulo apropriado. Essa definição funcional permite a afirmação da natureza da população de CTMs na ausência de marcadores específicos. O presente estudo se baseou nesse padrão e demonstrou a diferenciação pela avaliação citoquímica das três linhagens.

As diferenciações osteogênicas e adipogênicas deste estudo foram induzidas com concentração de $7,5 \times 10^{3}$ células $/ \mathrm{cm}^{2}$. Outros estudos utilizaram a concentração de $1 \times 10^{3}$ células $/ \mathrm{cm}^{2}$ para a diferenciação em adipócitos (Dvorakova et al., 2008) e $3 \times 10^{3} / \mathrm{cm}^{2}$ (Dvorakova et al., 2008; Colleoni et al., 2009) e $1 \times 10^{4} /$ poço (Im et al., 2005) para osteoblastos. É importante ressaltar o período de tempo que a monocamada leva para atingir a confluência desejada para início da indução. No presente estudo, o plaqueamento das células na concentração utilizada permitiu a obtenção da confluência em $24 h$.

Os protocolos de diferenciação adipogênica foram eficazes na formação de gotículas de gordura em três amostras dos dois tratamentos (Fig. 2A e B). Nas outras amostras, em ambos os tratamentos, as células morreram durante a indução. Não ocorreu diferenciação em amostras-controle (Fig. 2C). Neupane et al. (2008) utilizaram protocolo de diferenciação adipogênica semelhante ao deste trabalho, contudo relataram resultados limitados quanto ao número de células identificadas na avaliação citoquímica.

Neste estudo, utilizaram-se 200.000 células por tubo para a diferenciação condrogênica. Em outros estudos foram utilizadas 250.000 (Dvorakova et al., 2008), 500.000 (Colleoni et al., 2009) e 1.000 .000 células (Im et al., 2005). A diferenciação condrogênica realizada no sistema de cultura em micromassa necessita de um número mínimo de células para que o botão formado seja visível, podendo ser manipulado e corado. A concentração utilizada no presente trabalho foi suficiente para esse objetivo. A cultura de micromassa revelou presença de agregados tridimensionais tanto em tubos controle quanto nos de indução, sendo todos corados com azul de tripan $0,4 \%$. Porém, na análise dos cortes histológicos, demonstrou-se a presença de mucopolissacarídeos da matriz intracelular somente em duas amostras induzidas (Fig. 3A e B), dos dois tratamentos, não observada nas amostras-controle (Fig. 3C). A indução condrogênica ocorreu em três semanas, como relatado por Bunnell et al. (2008). 
Neupane et al. (2008) obtiveram indução em duas semanas, e Im et al. (2005) em quatro.

A indução osteogênica resultou na mineralização de focos com agregados celulares. Esse padrão também foi observado por Neupane et al. (2008). No presente estudo, o tempo de indução foi de três semanas, também descrito por Im et al. (2005) e Tapp et al. (2009). Foram observados depósitos de matriz extracelular em três das cinco amostras induzidas (Fig. 4A e B). Em duas amostras as células morreram durante a indução. Nas amostras-controle não foi observada presença de depósitos de matriz extracelular (Fig. 4C). Bunnell et al. (2008) e Neupane et al. (2008) descreveram indução com duas semanas, utilizando meios indutores com composições diferentes.

Os valores da atividade da FA foram mais elevados nas amostras-controle do que nas de diferenciação, compatível com os resultados encontrados por Martin et al. (2002) na indução osteoblástica de CTMs derivadas da medula óssea de gatos, contudo diferente dos resultados obtidos por Kadiyala et al. (1997), que observaram aumento de 10 vezes na atividade da FA em cultura osteogênica de células mesenquimais provenientes da medula óssea de cães. Zhu et al. (2008) relataram aumento na atividade da FA em células-tronco derivadas de tecido adiposo humano, da quarta passagem, após sete dias de cultura em meio osteogênico, entretanto os autores reportaram no mesmo estudo que células da passagem 25 apresentaram baixa atividade da FA.

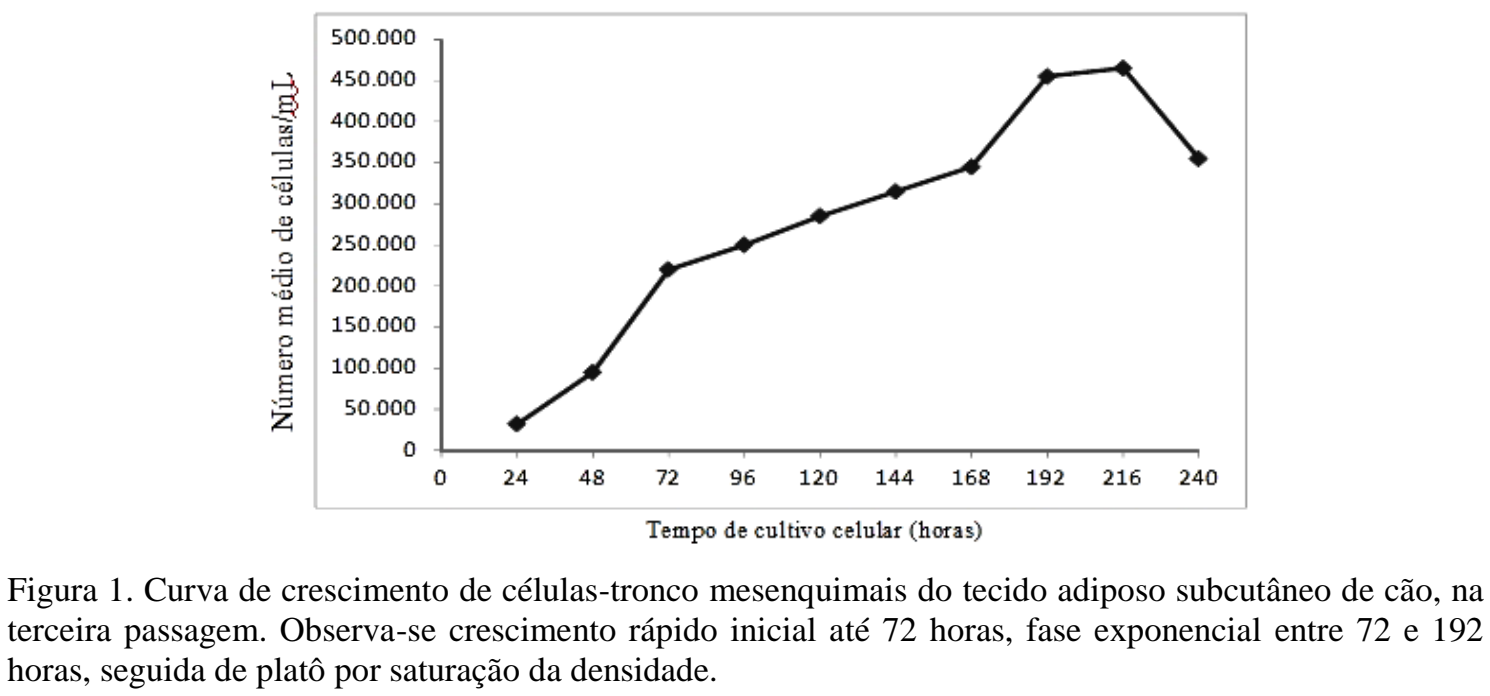

Figura 1. Curva de crescimento de células-tronco mesenquimais do tecido adiposo subcutâneo de cão, na terceira passagem. Observa-se crescimento rápido inicial até 72 horas, fase exponencial entre 72 e 192 horas, seguida de platô por saturação da densidade.
A caracterização morfológica das CTMs é importante para confirmar a espécie de origem, identificar a linhagem celular e a posição da célula dentro da linhagem (precursora ou status diferenciado), bem como para avaliar se as células apresentam características de malignidade (Freshney, 2005). O controle da morfologia celular e do tamanho das células e de suas organelas mostra-se relevante para $o$ desenvolvimento da diferenciação celular e dos órgãos e tecidos (Kharitonova e Vasiliev, 2008). As CTMs em cultivo apresentaram características fibroblásticas, com formato fusiforme, citoplasma basofílico e núcleos esféricos (Fig. 5A-D), em consonância com o trabalho de Vidal et al. (2007), que observaram as mesmas características em CTMs de cavalos, porém os autores não avaliaram a morfometria celular. $\mathrm{O}$ comprimento médio das células durante todo o estudo, nas três passagens, variou entre 80,85 e $98,36 \mu \mathrm{m}$, a largura média entre 17,40 e $28,79 \mu \mathrm{m}$, e a média do diâmetro do núcleo entre 15,46 e 17,74 $\mu \mathrm{m}$. Segundo Vasiliev (2004), no cultivo celular ocorrem alterações do número, do tamanho e da área das células, como observado no presente estudo. A forma da célula é controlada por estruturas do citoesqueleto interno e estruturas de adesão que fixam a célula à superfície e às outras células (Moizhess e Vasiliev, 2001; Rovensky et al., 2001). Na Tab. 1 , estão demonstrados os valores médios e o desvio-padrão dos parâmetros aferidos por passagem no período de medição, e na Tab. 2 estão os valores médios por período. 

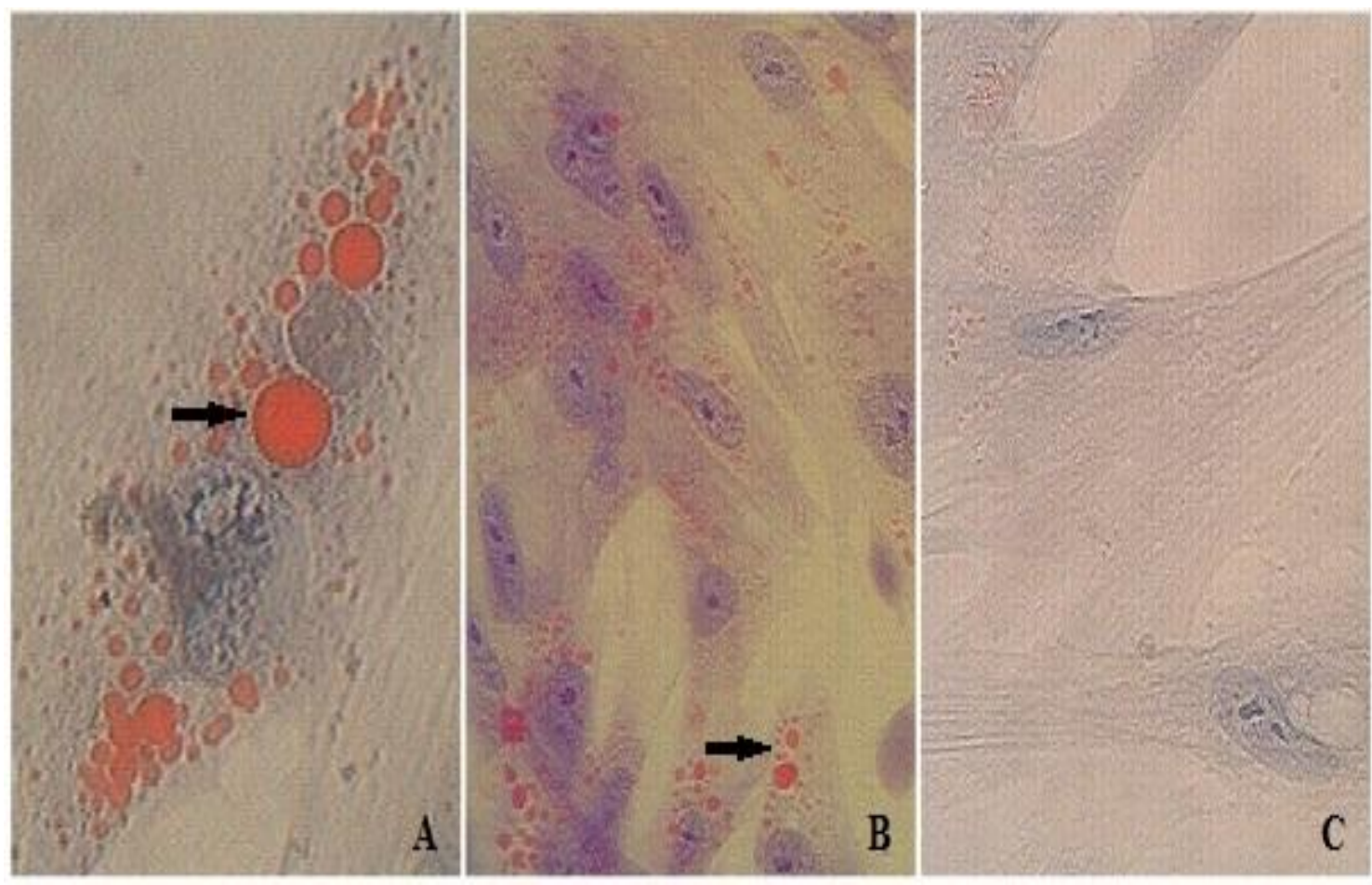

Figura 2. Diferenciação adipogênica de células-tronco mesenquimais do tecido adiposo de cão. Após 21 dias, foi possível observar a presença de gotículas de gordura coradas com o Oil Red $O$ (setas), nos tratamentos I (A) e II (B). As amostras-controle não apresentaram formação de gotículas de gordura (C).
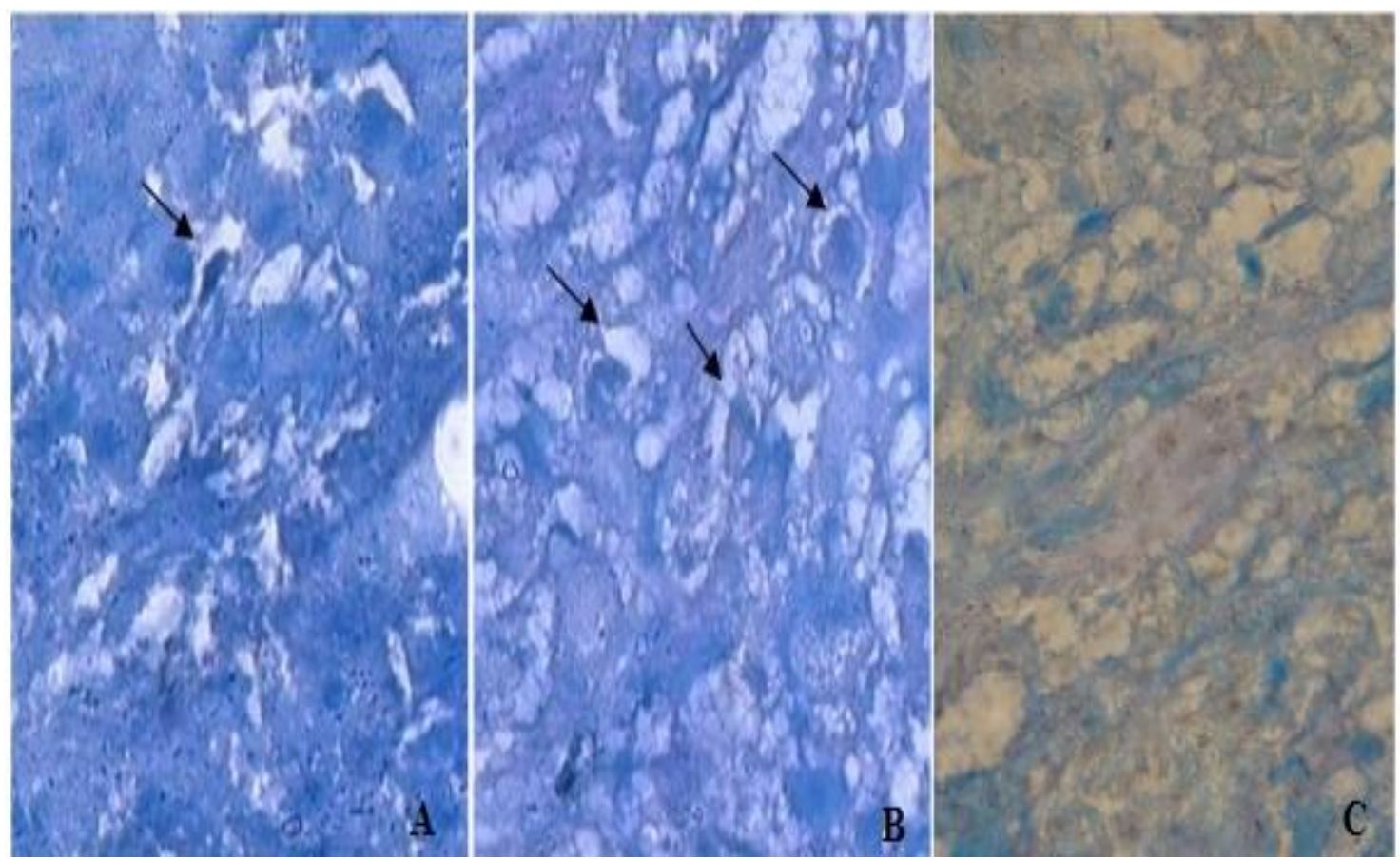

Figura 3. Diferenciação condrogênica de células-tronco mesenquimais do tecido adiposo de cão. Após 21 dias, foi possível observar mucopolissacarídeos da matriz intracelular corados com o azul de tripan 0,4\%, nos tratamentos I (A) e II (B), não observados nas amostras-controle (C). 


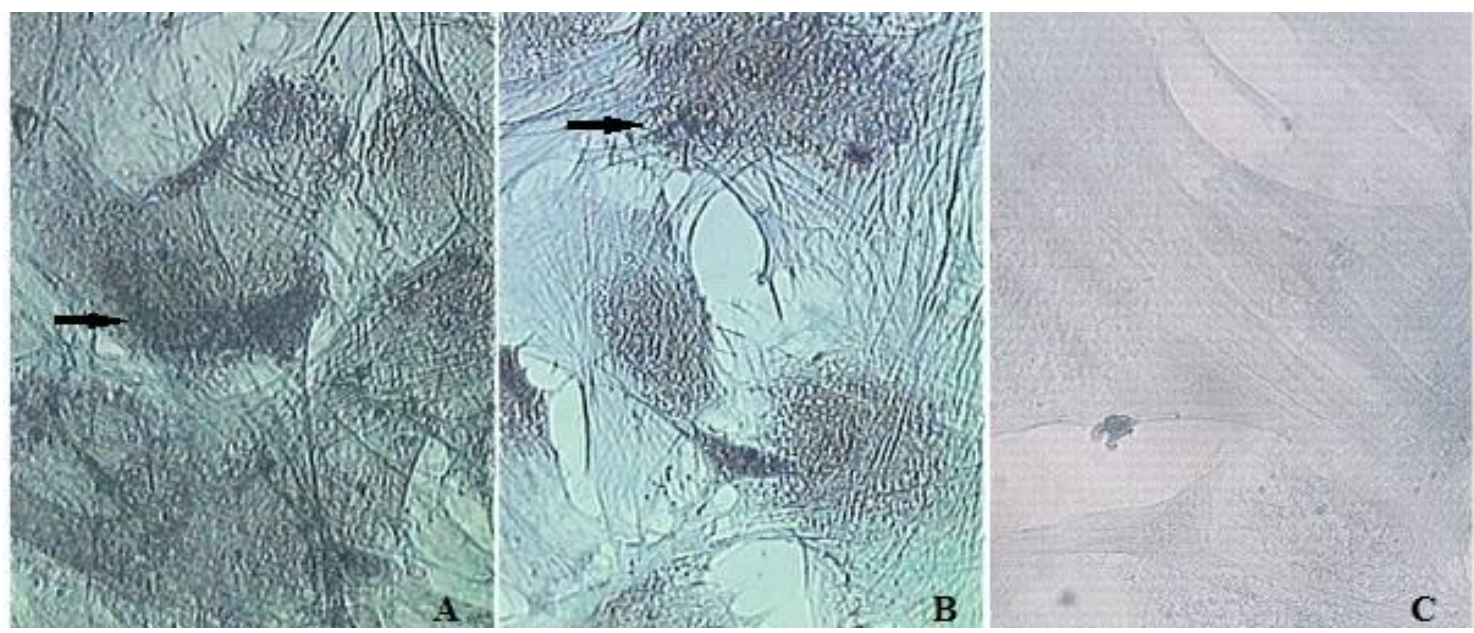

Figura 4. Diferenciação osteogênica de células-tronco mesenquimais do tecido adiposo de cão. Após 21 dias, foi possível observar a presença de depósitos de matriz extracelular corados com Alizarina Red S (A e B) (setas). As amostras-controle não apresentaram depósitos de matriz extracelular (C).

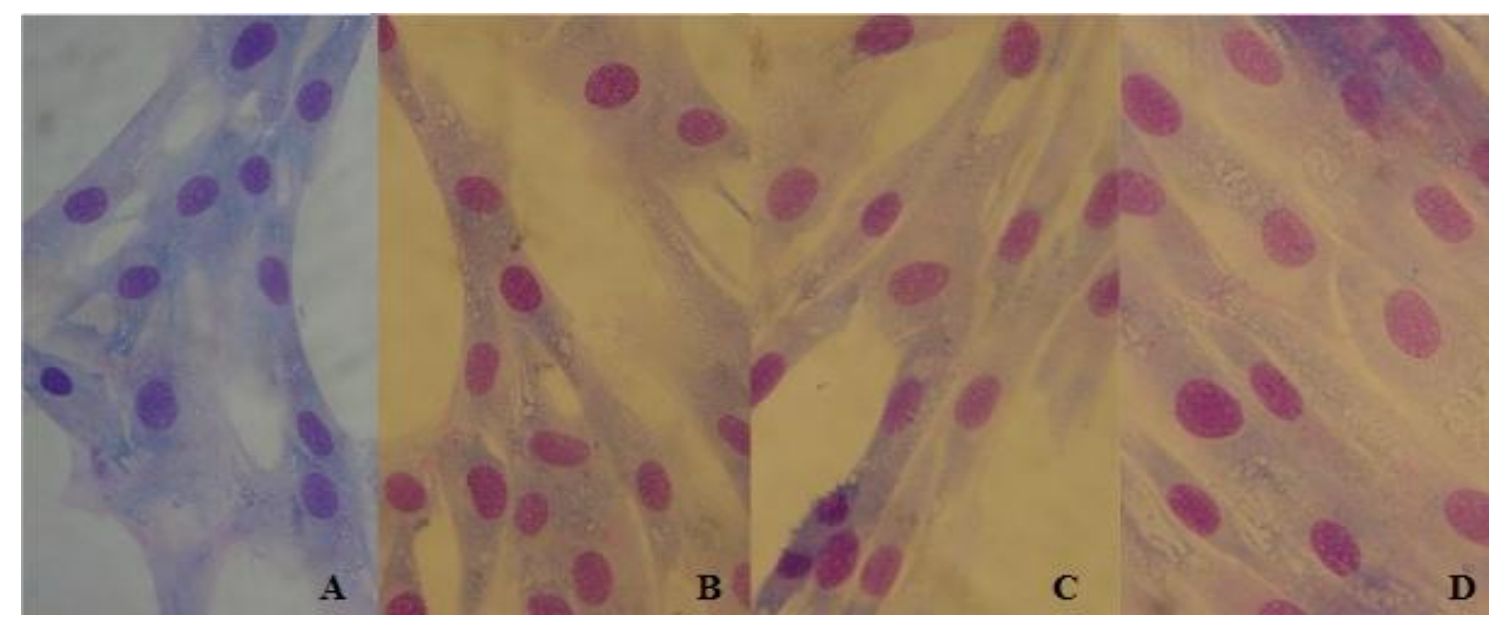

Figura 5. Células-tronco mesenquimais após 24 (A), 48 (B), 72 (C) e 96 horas (D) de cultivo (corante de Wright, $\mathrm{x} 400$ ).

Tabela 1. Valores médios \pm desvio-padrão dos parâmetros morfológicos mensurados nas CTMs isoladas das cinco amostras $(\mathrm{P}=$ Passagem $)$

\begin{tabular}{lcccc}
\hline $\mathrm{P}$ & $\begin{array}{c}\text { Tempo } \\
(\mathrm{h})\end{array}$ & Comprimento $(\mu \mathrm{m})$ & $\begin{array}{c}\text { Largura } \\
(\mu \mathrm{m})\end{array}$ & $\begin{array}{c}\text { Diâmetro do núcleo } \\
(\mu \mathrm{m})\end{array}$ \\
\hline & 24 & $68,01 \pm 21,44$ & $22,13 \pm 8,59$ & $16,25 \pm 4,42$ \\
$\mathrm{P} 1$ & 48 & $84,23 \pm 43,23$ & $24,43 \pm 10,69$ & $17,76 \pm 5,66$ \\
& 72 & $73,78 \pm 23,93$ & $21,13 \pm 8,71$ & $16,36 \pm 4,61$ \\
& 96 & $61,04 \pm 21,02$ & $19,57 \pm 6,22$ & $15,52 \pm 4,51$ \\
\hline & 24 & $74,59 \pm 28,52$ & $26,10 \pm 10,26$ & $17,87 \pm 5,62$ \\
& 48 & $60,64 \pm 19,67$ & $18,59 \pm 8,71$ & $13,87 \pm 4,65$ \\
& 72 & $62,57 \pm 25,63$ & $20,39 \pm 15,62$ & $14,45 \pm 4,82$ \\
& 96 & $65,42 \pm 23,13$ & $17,47 \pm 5,65$ & $14,44 \pm 4,89$ \\
$\mathrm{P} 3$ & 24 & $80,85 \pm 32,21$ & $20,40 \pm 10,04$ & $15,91 \pm 4,54$ \\
& 48 & $98,36 \pm 52,76$ & $28,79 \pm 22,05$ & $17,74 \pm 6,50$ \\
& 72 & $87,27 \pm 57,54$ & $18,36 \pm 5,46$ & $16,29 \pm 4,60$ \\
& 96 & $85,02 \pm 27,26$ & $17,45 \pm 5,11$ & $15,49 \pm 4,39$ \\
\hline
\end{tabular}


Isolamento e caracterização...

Tabela 2. Valores médios \pm desvio-padrão dos parâmetros morfológicos mensurados nas três passagens das CTMs das cinco amostras

\begin{tabular}{lccc}
\hline Tempo $(\mathrm{h})$ & Comprimento $(\mu \mathrm{m})$ & Largura $(\mu \mathrm{m})$ & Diâmetro do núcleo $(\mu \mathrm{m})$ \\
\hline 24 & $80,85 \pm 32,21$ & $20,40 \pm 10,04$ & $15,91 \pm 4,54$ \\
48 & $98,36 \pm 52,76$ & $28,79 \pm 22,05$ & $17,74 \pm 6,50$ \\
72 & $87,27 \pm 27,54$ & $18,36 \pm 5,46$ & $16,29 \pm 4,60$ \\
96 & $84,44 \pm 26,39$ & $17,40 \pm 5,09$ & $15,46 \pm 4,36$ \\
\hline
\end{tabular}

Estudos com CTMs de humanos descreveram as células em cultivo como células de morfologia fibroblástica (Barry e Murphy, 2004; Dvorakova et al., 2008), assim como estudos realizados com CTMs de camundongos (Sung et al., 2008; Tropel et al., 2004) e de cães (Csaki et al., 2007). Porém, em nenhum dos estudos com avaliação da morfologia das CTMs foi realizado o estudo morfométrico.

\section{CONCLUSÕES}

O tecido adiposo de cães é uma boa fonte de CTMs, sendo possível seu isolamento a partir de pequenas quantidades, coletadas em cirurgias eletivas. O meio DMEM/F12 suplementado com $15 \%$ de SFB pode ser utilizado para cultivo das CTMs. A diferenciação destas em adipócitos e condrócitos pode ser feita com meio comercial ou com meio de cultivo adicionado de indutores. As células isoladas são mesenquimais porque se diferenciaram em adipócitos, condrócitos e osteoblastos. A avaliação da atividade da FA não foi um bom marcador da diferenciação osteogênica das CTMs. As CTMs em cultivo têm características fibroblásticas, formato fusiforme, citoplasma basofílico e núcleos esféricos.

\section{REFERÊNCIAS}

BARRY, F.P.; MURPHY, J.M. Mesenchymal stem cells: clinical applications and biological characterization. Int. J. Biochem. Cell Biol., v.36, p.568-584, 2004.

BUNNELL, B.A.; FLAAT, M.; GAGLIARDI, C. et al. Adipose-derived stem cells: Isolation, expansion and differentiation. Methods, v.45, p.115-120, 2008.

CARVALHO, A.M.; ALVES, A.L.G.; GOLIM, M.A. et al. Isolation and immunophenotypic characterization of mesenchymal stem cells derived from equine species adipose tissue. Vet. Immunol. Immunopathol., v.132, p.303-306, 2009.
COLLEONI, S.; BOTTANI, E.; TESSARO, I. et $a l$. Isolation, growth and differentiation of equine mesenchymal stem cells: effect of donor, source, amount of tissue and supplementation with basic fibroblast growth factor. Vet. Res. Commun., v.33, p.811-821, 2009.

CSAKI, C.; MATIS, U.; MOBASHERI, A. et al. Chondrogenesis, osteogenesis and adipogenesis of canine mesenchymal stem cells: a biochemical, morphological and ultrastructural study. Histochem. Cell Biol., v.128, p.507-520, 2007.

DOMINICI, M.; LE, B.K.; MULLER, I. et al. Minimal criteria for defining multipotent mesenchymal stromal cells. The international society for cellular therapy position statement. Cytotherapy, v.8, p.315-317, 2006.

DVORAKOVA, J.; HRUBA, A.; VELEBNY, E. et al. Isolation and characterization of mesenchymal stem cell population entrapped in bone marrow collection sets. Cell. Biol. Int., v.32, p.1116-1125, 2008.

FRESHNEY, R.I. (Ed.) Culture of Animal Cells - A Manual of Basic Techniques. 5. ed. New York: Wiley-Liss, 2005. 641p.

IM, G.I.; SHIN, Y.W.; LEE, K.B. Do adipose tissue-derived mesenchymal stem cells have the same osteogenic and chondrogenic potential as bone marrow-derived cells? Osteoarthritis Cartilage, v.13, p.845-853, 2005.

KADIYALA, S.; YOUNG, R.G.; THIEDE, M.A. et al. Culture expanded canine mesenchymal stem cells possess osteochondrogenic potential in vivo and in vitro. Cell. Transplant., v.6, p.125-134, 1997.

KHARITONOVA, M.A.; VASILIEV, J.M. Controlling cell length. Semin. Cell Dev. Biol., v.19, p.480-484, 2008. 
MARTIN, D.R.; COX, N.R.; HATHCOCK, T.L. et al. Isolation and characterization of multipotential mesenchymal stem cells from feline bone marrow. Experim. Hematol., v.30, p.879-886, 2002.

MOIZHESS, T.G.; VASILIEV, J.M. Substrateinduced polarization of cultured epitheliocytes and fibroblasts: non-reactivity of Rastransformed cells. Cell Biol. Int., v.25, p.931934, 2001

NEUPANE, M.; CHANG, C.C.; KIUPEL, M. et al. Isolation and characterization of canine adipose-derived mesenchymal stem cell. Tissue Eng. Part A, v.14, p.1007-1015, 2008.

PITTENGER, M.F; MACKAY, A.M.; BECK. S.C. et al. Multilineage potential of adult human mesenchymal stem cells. Science, v.284, p.143147,1999

RODBELL M. Metabolism of isolated fat cells. II. The similar effects of phospholipase c (clostridium perfringens alpha toxin) and of insulin on glucose and amino acid metabolism. $J$. Biol. Chem., v.241, p.130-139, 1966.

ROVENSKY, Y.U.A.; DOMNINA, L.V.; IVANOVA, O.Y.U. et al. Responses of epithelial and fibroblast-like cells to discontinuous configuration of the culture substrate. Membr. Cell Biol., v.14, p.617-627, 2001.

SEKIYA, I.; COLTER, D.C.; PROCKOP, D.J. BMP-6 enhances chondrogenesis in a subpopulation of human marrow stromal cells. Biochem Biophys. Res. Commun., v.284, p.411418, 2001.
SUNG, J.H.; YANG, H.M.; PARK, J.B. et al. Isolation and characterization of mouse mesenchymal stem cells. Transplant. Proc., v.40, p.2649-2654, 2008.

TAPP, H.; HANLEY Jr., E.N.; PATT, J.C. et al. Adipose-derived stem cells: characterization and current application in orthopaedic tissue repair. Exp. Biol. Med., v.234, p.1-9, 2009.

TROPEL, P.; NÖEL, D.; LEGRAND, P. et al. Isolation and characterization of mesenchymal stem cell from adult mouse bone marrow. Exp. cell res., v.295, p.395-406, 2004.

VASILIEV J.M. Cytoskeletal mechanisms responsible for invasive migration of neoplastic cells. Int. J. Dev. Biol., v.48, p.425 439, 2004.

VIDAL, M.A.; KILROY, G.E.; LOPEZ, M.J. et al. Characterization of equine adipose tissuederived stromal cells: adipogenic and osteogenic capacity and comparison with bone marrowderived mesenchymal stromal cells. Vet Surg., v.36, p.613-622, 2007.

WAGNER, W.; WEIN, F.; SECKINGER, A. et al. Comparative characteristics of mesenchymal stem cells from human bone marrow, adipose tissue, and umbilical cord blood. Exp. Hematol., v.33, p.1402-1416, 2005.

ZAGO, M.A. Terapia com células-tronco: fundamentos, oportunidades e obstáculos. Hipertensão, v.8, p.145-150, 2005.

ZHU, Y.; LIU, T.; SONG, K. et al. Adiposederived stem cell: a better stem cell than BMSC. Cell Biochem Funct. v.26, p.664-675, 2008. 